\section{Correcting the misperceptions surrounding osteopathic medicine}

During the past 20 years, osteopathic medicine has experienced explosive growth, making it the most rapidly expanding health profession during that period. In 1969, there were slightly more than $13,000 \mathrm{DOs}$. Today, we number approximately 29,000 strong. Our growth can be attributed, in part, to the public's demand for primary care physicians.

A great majority of osteopathic physicians practice general practice medicine. We provide care to an estimated $10 \%$ of all Americans. Osteopathic physicians represent $20 \%$ of all family doctors in the United States. DOs serve as physicians in the armed services, and the public health service, on professional sports teams, and even in the Olympics. Despite all these accomplishments, our role in society remains greatly misunderstood. Many people believe that the MD is the only comprehensive healthcare professional in America.

See Dr Murray Goldstein's article, beginning on page 157.

The misperceptions surrounding our profession require reiteration and clarification of the osteopathic medical philosophy, which is based on the Hippocratic philosophy of medicine.

Paramount to our philosophy is a recognition that the physical body, mind, and spirit are a triumvirate that forms one human, biological unit. Nature's healing power provides the body with the ability to maintain health and combat disease. Furthermore, the integrity of the musculoskeletal system proves critical for maintaining good health. Therefore, mechanical disorders of the musculoskeletal system can affect all body functions. In turn, such malfunctions hinder the body's natural ability to sustain health.
Of all these components, the musculoskeletal element has been the most misconstrued. At times, it has been distorted to suggest that the osteopathic physicians' training and practice are limited. In fact, DOs receive as comprehensive training as modern medicine permits. Our training encompasses all branches of medicine and surgery. With a particular emphasis on health promotion and disease prevention, we can and do contribute something more to the healthcare of all Americans.

Nearly 100 years after the first osteopathic medical college was founded, approximately 7000 students are enrolled at today's 15 colleges of osteopathic medicine. Most of these future physicians will end up practicing in small towns and in rural areas.

Clearly, the basic philosophy expressed in osteopathic medicine, a holistic approach to health promotion and disease prevention, a focus on primary care, and a return to peopleoriented, rather than disease-oriented, care is an idea whose time has come. Rheumatologists, neurologists, and sports medicine physicians, along with primary care physicians, are recognizing the importance of the musculoskeletal system and manipulative treatment for structural and mechanical disorders.

An organized medical philosophy for the past 100 years, osteopathic medicine remains, perhaps, one of the world's best kept secrets. It's time to share our secret with society at large.

THOMAS WESLEY ALLEN, DO Editor in Chief

\section{Mandatory in-flight medical equipment earns high marks}

In a 1980 editorial, "A plea to the airlines," (JAOA 1980;79:430) I urged airlines to have basic medical equipment kept on board for phy-

(continued on page131) 


\section{POSTHERPETIC NEURALGIA}

There Are Many Words To Describe The Pain.

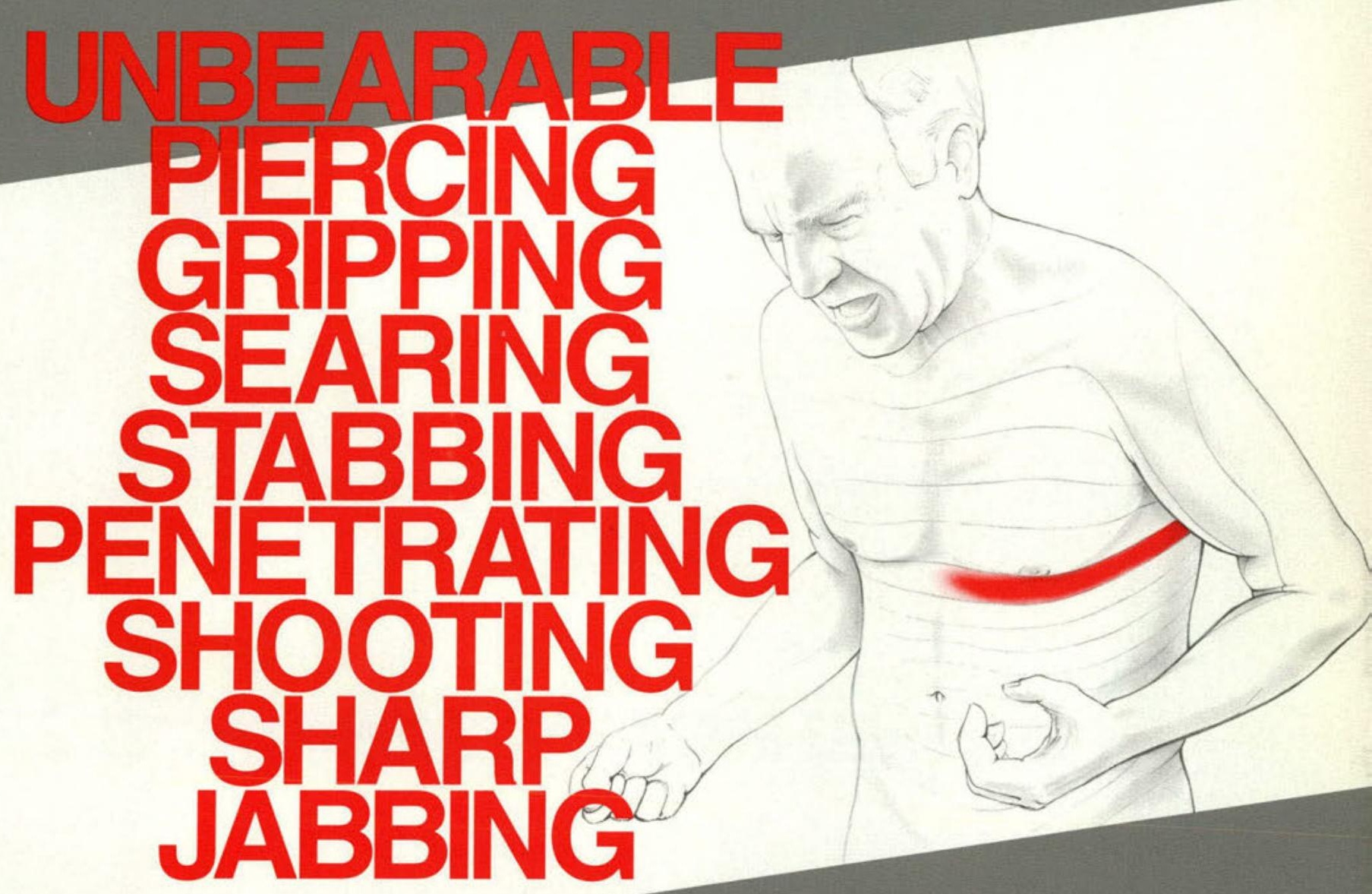

And One For Treating It.

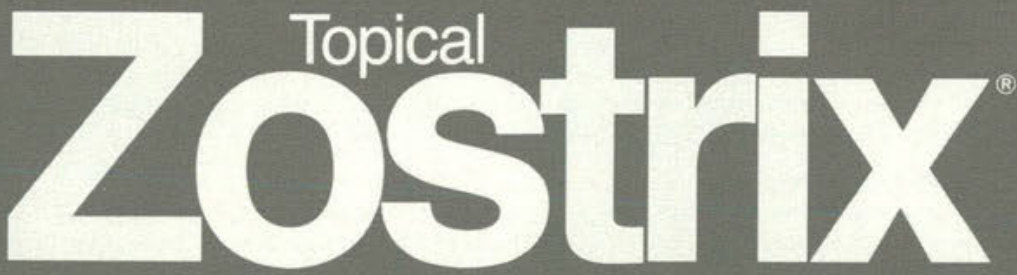

(Capsaicin 0.025\%) Cream

When patients describe the "hurt" of postherpetic neuralgia (PHN), they use a wide range of words to describe a pain that is often intractable and difficult to treat. Zostrix ${ }^{\oplus}$ (Capsaicin $0.025 \%$ ) Cream provides an effective topical treatment that alleviates intense pain in most PHN patients.

Topical Zostrix Works Where It Hurts

Now Available in 3 oz. Economy Size 


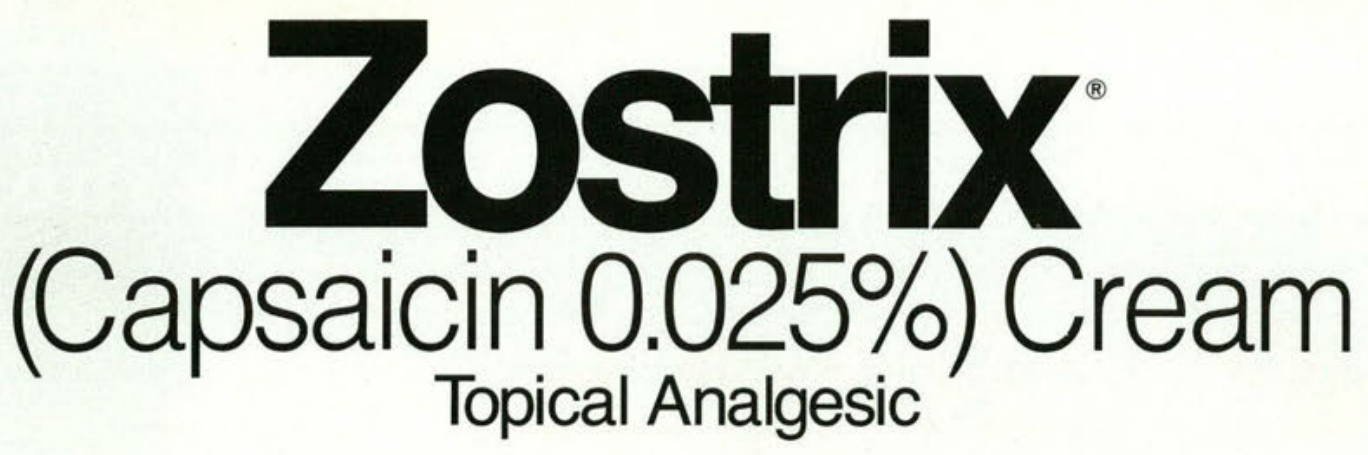

TARGETED ACTION

Acts on sensory nerves at site of application by selectively depleting substance $P$, a chemomediator of pain impulses along neuropathways.

\section{EFFECTIVE}

Alleviates the intense pain associated with postherpetic neuralgia in most patients. May also benefit patients when added to existing systemic drug regimens.

\section{SAFE}

No known interactions with systemic medications commonly prescribed for geriatric patients.

\section{Topical Zostrix Works Where It Hurts}

\section{DESCRIPTION}

Zostrix Cream contains capsaicin $0.025 \%$ in an emollient base. Capsaicin is a naturally occurring substance derived from plants of the Solanaceae family with the chemical name trans-8-methyl- $\mathrm{N}$-vanillyl-6-nonenamide. Capsaicin is a white crystalline powder with a molecular weight of 305.4 . It is practically insoluble in water but very soluble in alcohol, ether and chloroform.

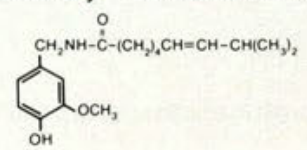

\section{ACTIONS AND INDICATIONS}

Although the precise mechanism of action of capsaicin is not fully understood, current evidence suggests that capsaicin renders skin insensitive to pain by depleting and preventing reaccumulation of substance $P$ in peripheral sensory neurons. Substance $\mathrm{P}$ is thought to be the principal chemomediator of pain impulses from the periphery to the central nervous system. Zostrix Cream is indicated for the temporary relief of the pain (neuralgia) associated with and following episodes of herpes zoster infections after open skin lesions have healed.

\section{WARNINGS}

For external use only. Avoid contact with eyes and broken or irritated skin. Do not bandage tightly. If condition worsens, or if symptoms persist for more than 14 days or clear up and occur again within a few days, discontinue use of this product and consult your physician. Keep this and all drugs out of the reach of children.

\section{DIRECTIONS}

Adults and children 2 years of age or older: Apply Zostrix to affected area not less than 3 or 4 times daily. Zostrix may cause transient burning on application. This burning is observed more frequently when application schedules of less than 3 or 4 times daily are utilized. After Zostrix is applied with the fingers, the hands should be washed immediately.

\section{HOW SUPPLIED}

$1.5 \mathrm{oz}$. tubes (NDC 52761-552-45)

\section{Marketed by GENDERM ${ }^{\circledR}$ Corporation}

Northbrook, IL 60062 
sician passengers to use in medical emergencies. My plea was the result of a personal experience, which I shared in that editorial:

"While on board a jet about to depart from Chicago, a passenger had suffered a cardiac arrest. The call went out for any physicians on board; two DOs responded. (I was one of them.) By the time we had reached the back of the plane, where the stricken passenger was stretched out in the aisle, cardiopulmonary resuscitation already had begun. The only medical equipment available on the plane was a rather ancient stethoscope and a blood pressure unit that had seen better days. Fortunately, because of everyone's efforts, the passenger was kept 'going' until the paramedics arrived with their equipment."

This JAOA editorial was not the first article to express public concern over the lack of available in-flight medical equipment. Yet, television from coast-to-coast broadcast it in part during nightly newscasts. Donald Siehl, DO, past AOA president, sent copies of the editorial to the major airlines' medical departments.

Their replies were less than enthusiastic, sometimes bordering on the outrageous. For example, one physician responded saying that "these deaths generally [happened to] older people, frequently with a terminal illness, [who were] on their way home to die."

The debate continued on the need for inflight medical equipment. Finally, on Aug 1, 1986, the Federal Aviation Administration (FAA) instituted new regulations requiring additional medical supplies be on board all United States aircraft carrying 30 or more passengers.

Nearly 3 years after this ruling, researchers published the results of their study, which examined one airline's experience with having available improved in-flight medical equipment. The medical kits were used 362 times on 361 flights during a 1-year period. Every physician who is willing to answer the call, "Is there a doctor on board?" should read this article (JAMA 1989;262:1653-1656).

The FAA deserves our compliments on their response to public and professional concerns in this area. As one foreign airline medical director said, “....as doctors have willingly given assistance when required, it should be our responsibility to provide a reasonable range of emergency equipment and medication to make their contribution something better than first aid."

To that I say, "Amen."

GEORGE W. NORTHUP, DO Editor Emeritus 

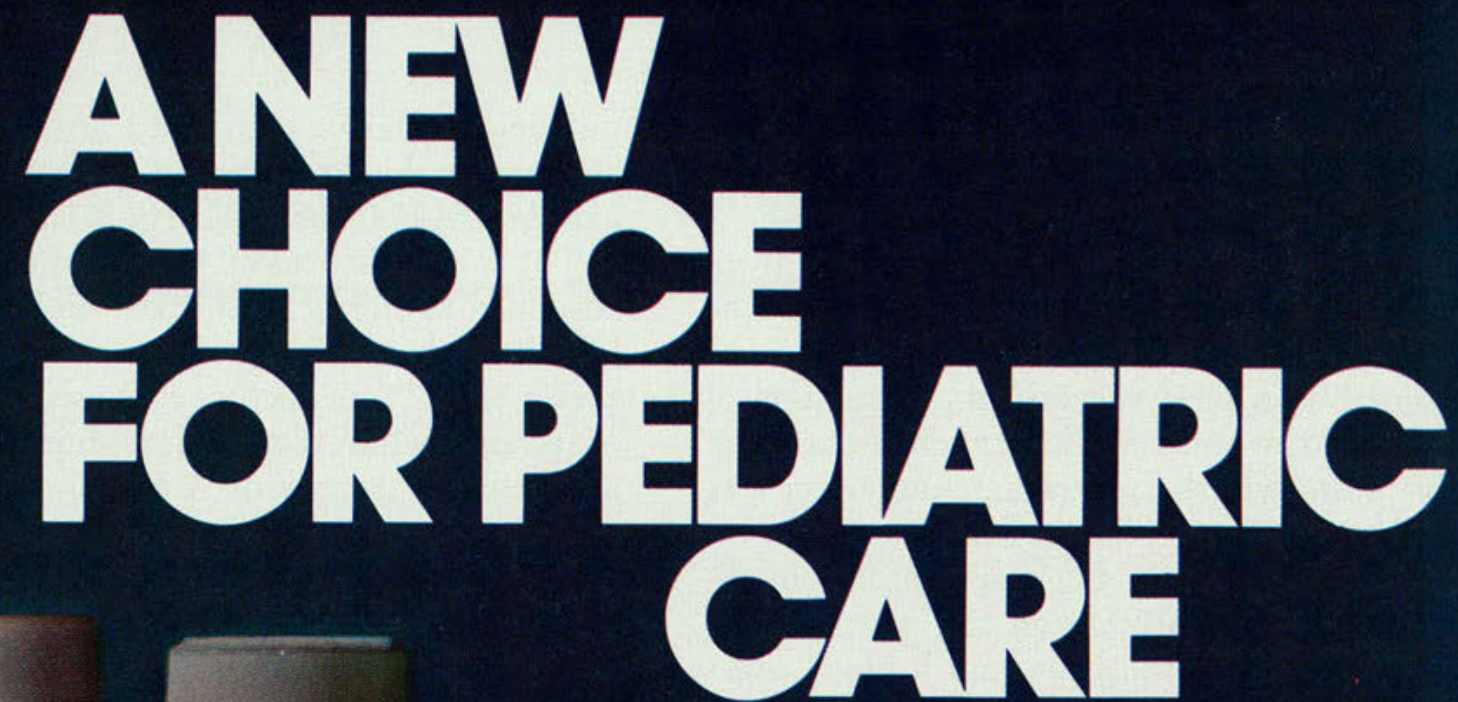

$\theta$

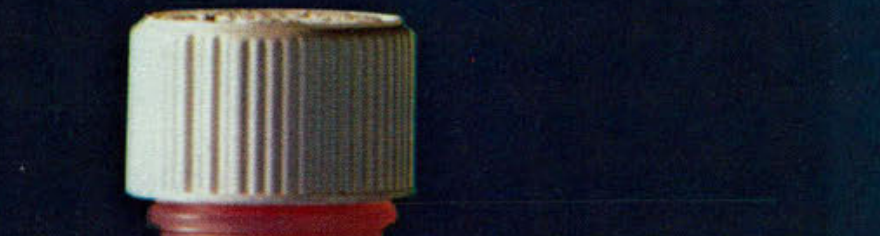

berenomer nuvo on

E

Naviosin

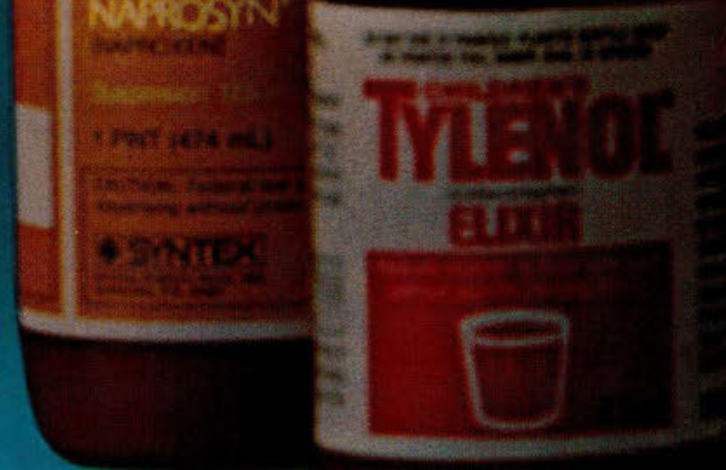




\section{EFFECTIVELY REDUCES FEVER}

Clinical trials have documented the significant antipyretic efficacy of Children's Advil (ibuprofen) Suspension. ${ }^{1.2}$

\section{EFFECTIVELY REDUCES INFLAMMATION IN JUVENILE ARTHRITIS}

Children's Advil ${ }^{\circledR}$ (ibuprofen) Suspension produced significant improvement in all efficacy parameters - including number of swollen and painful joints, grip strength, and duration of morning stiffness. ${ }^{3}$

\section{WELL TOLERATED}

at clinically effective doses ranging from 20 to $50 \mathrm{mg} / \mathrm{kg} / \mathrm{day}$

\section{BY PRESCRIPTION ONLY}

Please see following page for a brief summary of prescribing information.
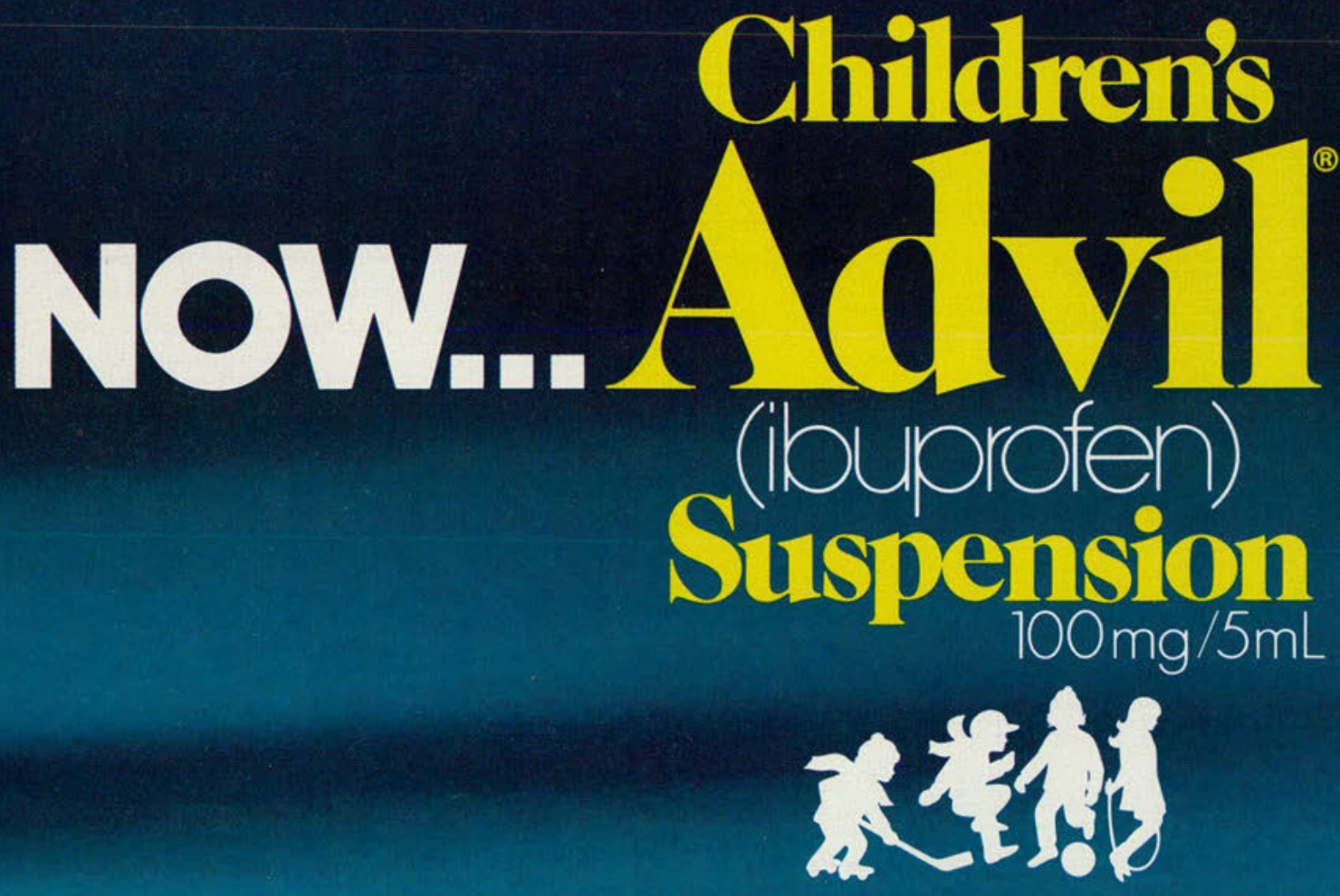


\section{Children's}

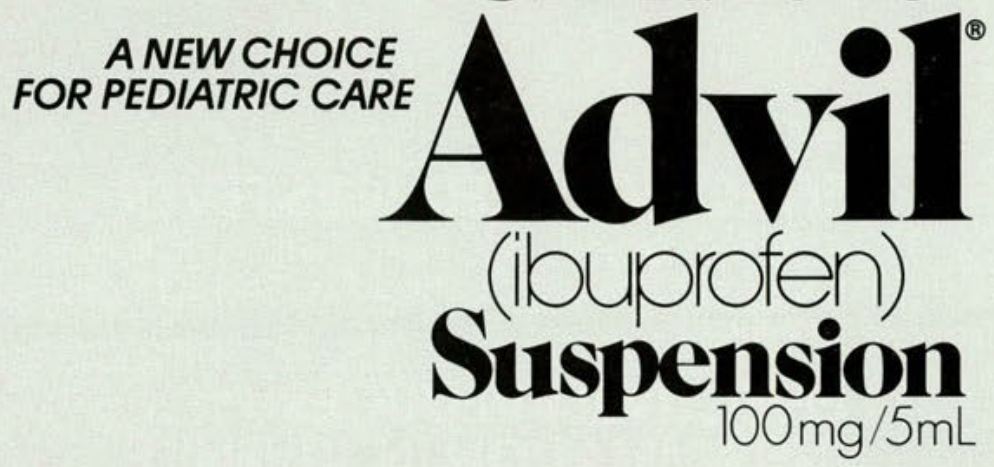

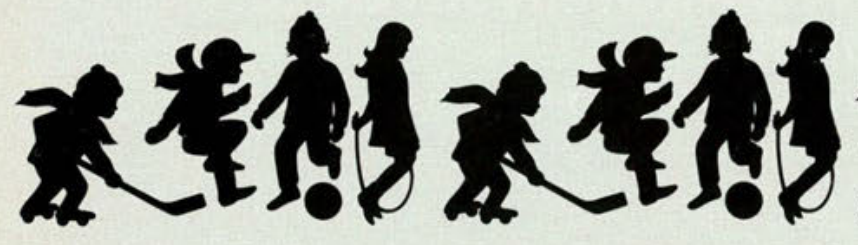

BRIEF SUMMARY OF PRESCRIBING INFORMATON

CONIRAINDICAMIONS: Patients hypersensitive to ibuproten or patients with all or part of the syndrome of nasal polyps, angioedema, and bronchospastic reactivity to aspirin or other nonsteroida antilinfiammatory ogents. Anaphylactoid reactions to ibuprofen have occurred in such patien should remain of Ulcerations, Bleeding, and Pertoration with NSAD Therapy: Physicians should remain alert for ulceration and bleeding in patients treated chronically with NSAib Seven in the absence of previous Gl tract symptoms. In patients observed in clinical frials of several months'

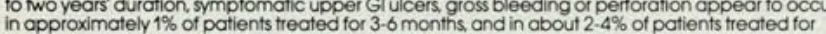
one year.

Except for a prior history of serious Gl events and other risk factors known to be associated with pep. fic ulcer disease, no risk factors have been associated with increased risk Elderly or debilitated patients seem to tolerate ulceration or bleeding less well than other individuals and most sponta

neous reports of fatal Gl events are in this population.
PRECAUnONS: Generat: Because serious GI tract ulceration and bleeding can occur without warning symptoms, physicians should follow chronically treated patients for the signs and symp toms of ulceration and bleeding

a polor vision have been reported. If a patient develops such complaint

Fluid retention and examination. with caution in patients with a history of cardiac decompensation or hypertension

Ibuprofen can inhibit platelet aggregation and prolong bleeding fime. CHILDRENS ADVL

SUSPENSION should be used with caution in persons with intrinsic coagulation defects and those

on anticoagulant therapy.

The antipyrefic and anti-inflammatory activity of ibuprofen may reduce fever and inflammation, thus diminishing their utlity as diagnostic signs in detecting complications of presumed noninfec

tious, noninflammalory painflul conditions.

Small decreoses (Usually not exceeding one gram) in hemoglobin and hematocrit with an appa

ent dose response relationship have been observed folliow

no signs of bleeding it is probably not clinically important. therapy should hove their therapy tapered slowly when CHILDRENS ADVIL S SUSPENSION is added to the treatment program

Aseptic meningitis: Aseptic meningitis with fever and coma has been observed on rare occasion in adult patients on ibuprofen therapy. Although it is more likely to occur in patients with systemic lupus erythematosus and related connective tissue disecses, it has been reported in adult patients

who do not have underlying chronic disease. If signs or symptoms of meningitis develop in a
patient on CHILDRENS ADV VIL SUSPENSION. the possibility of its being related to ibuproten should be

Renal Effects: As with other nonsteroidal anti-inflammatory drugs, long-term administration of ibuprofen to animals has resulted in renal papillary necrosis and other abnormal renal patholog in humans, there have been repp

A second form of renal toxicity hos been seen in patients with prerengl conditions leading to reducfion in renal blood flow or bload volume in these patients administration of ansteroidol antinflammatory drug cipitate overt renal decompensation. Patients at greatest risk of this reaction are those with impaired renal function, heart failure, liver dysfunction, and those taking diuretics and the elderty. Those patients at high risk who chronically take CHILDRENS ADVL: SUSPENSION should have rene function monitored if they have signs or symptoms of azotemia. Discontinuation of nonsteroidal anti-inflammatory drug therapy is typically followed by recovery to the pretreatment state. Since ibuprofen is eliminated primarily by the kidneys, patients with significantiy impaired renal function should be closely monitored and a reduction in dosage should be anticipated to avold drug accumulation.

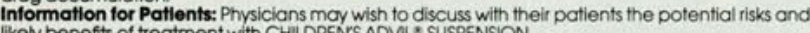
(a) SUSPENSION

Laboratory iests: Meaninglal (Stimes test suggesting liver dysfunction or in whom an abnormal liver test has occurred should be evaluated for evidence of the development of more severe hepatic reactions while on therapy with ibuprofen. If abnormal itver tests persist or worsen if clinical signs and symptoms consistent with liver disease develop, or if systemic manifestations Occur, CHILDRENS ADVIL * SUSPENSION should be discontinued.

Dlabetes: EOch $5 \mathrm{~mL}$ of CHILDRENS ADVIL * SUSPENSION contains $25 \mathrm{~g}$ of sucrose which should be taken into consideration when treating patients with impaired glucose tolerance. It also contains $350 \mathrm{mg}$ of sorbitol per $5 \mathrm{~mL}$. Although in clinical trials CHILDRENS ADVL * SUSPENSION was not associated with more diarrhea than control treatments, should a patient develop diarrhea, the physi-

Drug Interactions: Coumarin-type Anticoagulants: Bleeding has been reported when ibuprofen marin-type anticoagulants: the physician should be cautlous when administering marin-type anticoagulants: the physician should be
ADVI SUSPENSION to patients on anticoagulants.

Aspirin: Concurrent use of aspirin is not recommended.

Methotrexate: In vitro studies indicate that ibuprofen could enhance the toxicity of methotrexate. Caution should be used if CHILDRENS ADVI * SUSPENSION is administered concomitantly with methotrexate

$\mathrm{H}_{2}$ Antagonists: in studies with human volunteers, coadministration of cimetidine or ranitidine with ibuproten had no substantive effect on ibuprofen serum concentrations.

Furosemide: Ibuprofen can reduce the natriuretic effect of furosemide and thiazides in some patients. During concomitant therapy with CHILDRENS ADVIL SUSPENSION, the patient should be

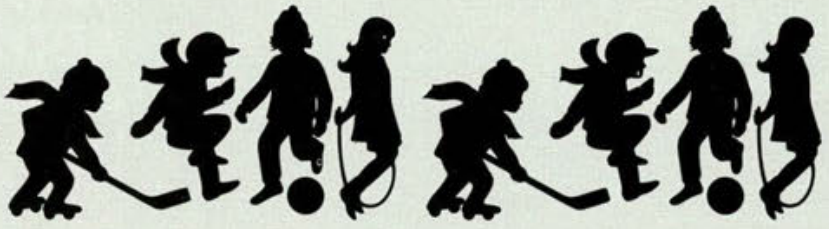

observed closely for signs of renal failure as well as to assure diuretic efficacy Uithium: Ibuprofen produced an elevation of plasma lithium levels (15\%) and a reduction in rena administration. Patients should be observed carefully for signs of lithium toxicity. Read package insert for lithium before its use.

Pregnancy: Administration of ibuprofen is not recommended during pregnancy or for use by nursing mothers.

Infants: Safety and efficacy of CHILDRENS ADVI * SUSPENSION in children below the age of ADVERSE REACIIONS: The most frequent type of adverse reaction occurring with CHILDRENS ADVL * SUSPENSION is gastrointestinal. In clinical trials among odults involving chronic administration of ibuproten, the percentage of patients reporting one or more gastrointestinal complaints ranged

Incidence Greater Than $1 \%$ (but less than 3\%), Probable Causal Relationship

Gastrointestinal: Nausea" epligastric pain" heartburn" diarrhea, abdominal distress, nausea and

(bloating and

Central Nervous System: Dizziness: headache, nervousness.

Special Senses: Tinnitis.

Metabolic/Endocrine: Decreased appetite

Cardiovascular. Edema, fluid retention (generally responds promptly to drug discontinuation)

(SOe PRECAUTIONS)

Reactions occurring in $3 \%$ to $9 \%$ of adult patients treated with ibuprofen

Precise Incidence Unknown (but less than \$\%), Probable Causal Relationship

Gastrointestinal: Gastric or duodenal ulcer with bleeding and/or perforation gastrointestinal hem

orrhage, pancreatifis, melena, gastritis, hepatitis, jaundice, abnormal liver function tests.

Dermatologic: Vesiculobuilous eruptions, unticana, eny hemamultorme, Siever

drome, alopecia

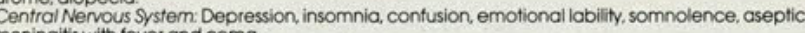

Speciol Senses Hecring come

(see amblyopia (blurred and/or diminished vision scotomata and/or changes in co: rvision) (sEe PRECAUNIONS)

Hematologic: Neutropenia, agranulocytosis, aplastic anemia hemolytic anemia (sometimes Coombs positive), thrombocytopenia with or without purpura, eosinophilia, decreases in

hemoglobin and hematocrit (see PRECAUTIONS).

Cardiovascular: Congestive heart fallure in patients with marginal cardiac function elevated

Aliergic: Syndrome of abdominal pain fever, chills, nausea and vomiting anaphyloxis, bronchosposm (see CONTRAINDICATIONS),

(see PRECAUTIONS), decreased creatinine clearance, polyuria, azotemia cystitis, hematuric

Precise incidence Unknown (but less than 1\%), Causal Relationship Unknown

Ceniral Nervous system: Paresthesias, hallucinations, dream abnormalities, pseudotumor cerebri.

Dermato

Special Senses Conjunctivitis, diplopia optic neuritis, cataracts.

Hematologic: Bleeding episodes (eg epistaxis, menorrhagia).

Cardiovoscular: Arrhythmigs (sinus tia, hypoglycemic reactions, acidosi

Aliergic: Serum sickness, lupus erythematosus syndrome, Henoch-Schönlein vasculitis, angioedeme Renat: Renal papillary necrosis.

OVERDOSAGE: Patients with a history of ingestion of greater than $100 \mathrm{mg} / \mathrm{kg}$ should have induced emesis or gastric lavage. Multiple dose oral administration of activated charcoal may be usefu drug is acidic and excreted in the urine, administration of sodium bicarbonate and induction of diuresis may be beneficia

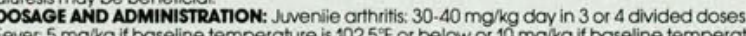
gif baseline temperature is $102.5^{\circ} \mathrm{F}$ or below or $10 \mathrm{mg} / \mathrm{kg}$ if baseline temperature is greater than $102.5 \%$ every 6.8 hours (children): $400 \mathrm{mg}$ every 4.6 hours (adults)

Mild to OA: $1200-3200 \mathrm{mg}$ per day in 3 or 4 divided doses

Dysmenorihec: $400 \mathrm{mg}$ every 4 hours
HOW SUPPLED: 4 and 16 oz bottles

Caution: federal law prohibits dispensing without prescription.

References:

1. Walson PD, Galletta G, Braden NJ, Alexander L Ibuprofen, acetaminophen, and placebo treat

2. Independent Clinical Study. Reduction of Fever in Children, Multiple Dose. Data on fle. Medical

3.

nile Arthritis. Data on file, Medical Department, Whitehall

WHITEHALL LABORATORIES

A HEALTH CARE DMISION OF

AMERICAN HOME PRODUCTS CORPORATION

(c) 1989 Whitehall Laboratories, N.Y, N.Y. 


\section{FROM THE WORK OF A FEW . . . FOR THE BENEFIT OF MANY}

"... The whole of my remaining realizable estate shall be dealt with in the following way: the capital, invested in safe securities by my executors, shalf constitute a fund, the interest on which shall be annually distributed in the form prizes to those who, during the preceding year, shall have conferred the greatest benefit on mankind..."
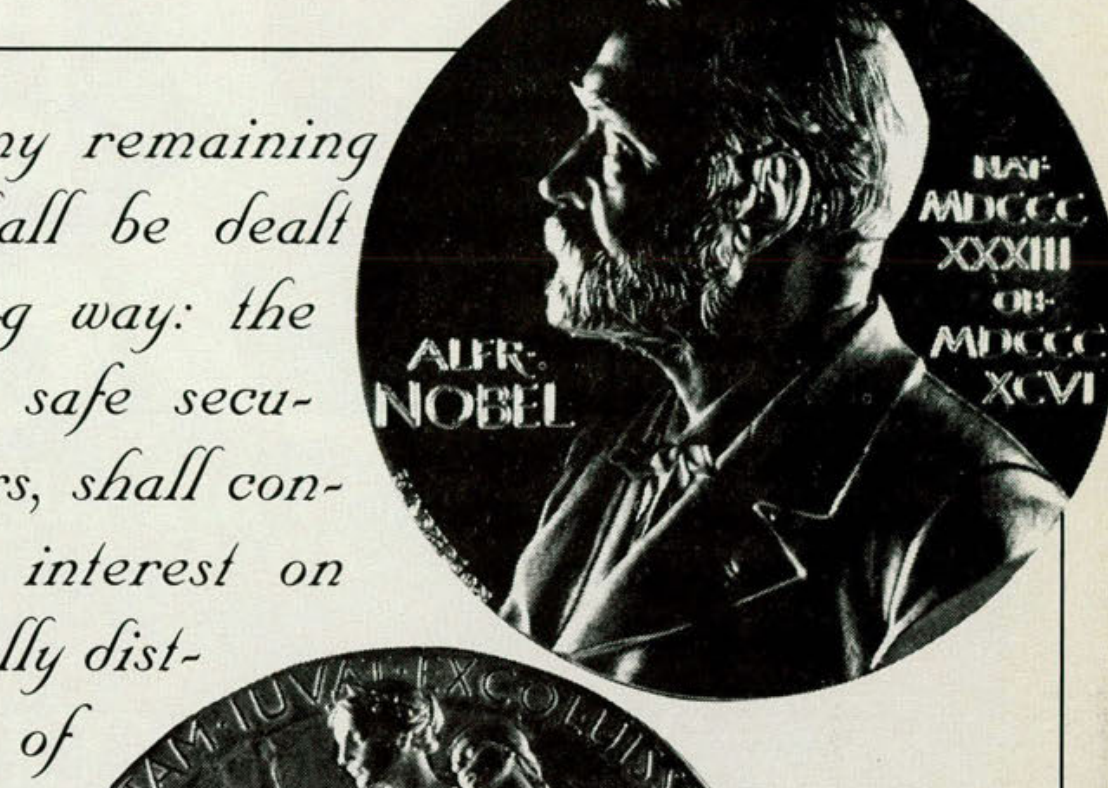

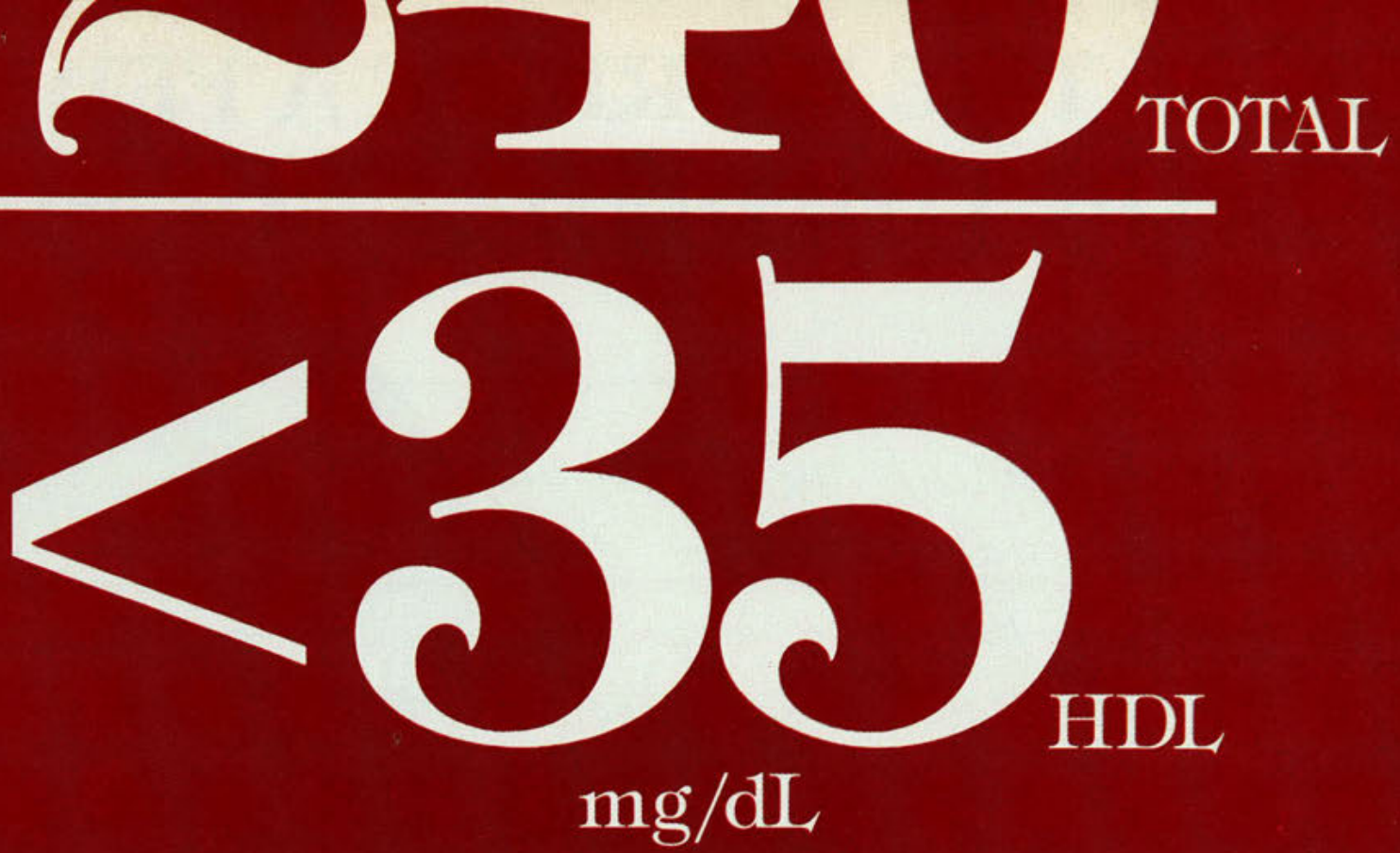

What's a common denominator of most heart attack victims?

Mixed hyperlipidemias-elevated cholesterol and triglycerides-are common among heart attack victims, ${ }^{1}$ and nearly two-thirds of people who developed myocardial infarction in the PROCAM Trial had a low $(<35 \mathrm{mg} / \mathrm{dL})$ baseline level of HDL cholesterol. ${ }^{2}$

HEART ATTACK PATIENTS $(\text { PROCAM TRIAL) })^{2}$

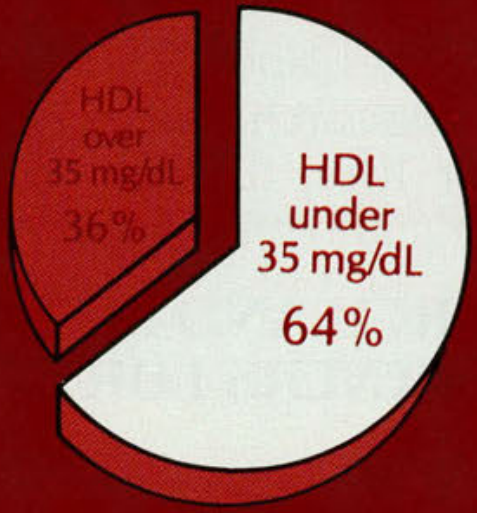




\section{A powerful case for
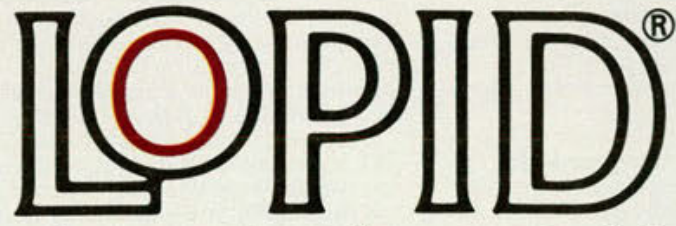 \\ Lopid \\ $\mathrm{BID}$ (gemfibrozil) ${ }_{\text {Tablets }}^{600-m g}$}

\section{Raised low HDL 25\%}

- in patients whose baseline HDL was below

$35 \mathrm{mg} / \mathrm{dL}$ in the landmark Helsinki Heart Study (HHS). ${ }^{3}$

\section{Reduced heart attack incidence* up to $62 \%$}

-in these HHS patients and $45 \%$ in HHS patients whose baseline HDL was below the median $(46.4 \mathrm{mg} / \mathrm{dL})$. Incidence of serious coronary events was similar for LOPID and placebo subgroups with baseline HDL above the median $(46.4 \mathrm{mg} / \mathrm{dL}){ }^{3}$

\section{Raised HDL levels $1 \frac{1}{2}$ to 3 times more effectively than lovastatin}

-in a 12-week, double-blind, randomized trial among patients with moderate to severe hyperlipidemia.

Lovastatin achieved greater reductions in total serum cholesterol than gemfibrozil in this study population. ${ }^{4}$

\section{RAISES HDL}

\section{DRAMATICALLY REDUCES HEART ATTACK}

LOPID is indicated for reducing the risk of coronary heart disease

(CHD) in Type Ilb patients with low HDL, in addition to elevated LDL and triglycerides, and who have had an inadequate response to weight loss, diet, exercise, and other pharmacologic agents such as bile acid sequestrants and nicotinic acid.

*Defined as a combination of definite coronary death and/or definite myocardial infarction.

References: 1. Goldstein JL, Hazzard WR, Schrott HG, Bierman EL, Motulsky AG. Hyperlipidemia in coronary heart disease. I. Lipid levels in 500 survivors of myocardial infarction. I Clin Invest. 1973;52:1533-1543. 2. Assmann G, Schulte H. PROCAM-Irial: Prospective Cardiovascular Münster Trial. Zürich: Panscientia Verlag; 1986:8-9. 3. Data on file, Medical Atfairs Dept, Parke-Davis 4. Tikkanen MJ, Helve E, Jaattela A, et al. Comparison between lovastatin and gemiabrozil treatment of prims
$1988 ; 62: 35)-43$.

Please see last page of this advertisement for warnings,

contraindications, and brief summary of prescribing information. 
Lopid ${ }^{*}$ (Gemfibrozil Capsules and Tablets)

Before prescribing, please see full prescribing information.

A Brief Summary follows.

CONTRAINDICATIONS. 1. Hepatic or severe renal dysfunction, including primary

2. Preexisting gallbladder disease (See WARNINGS)

3. Hypersensitivity to gemfibrozil.

WARNINGS. 1. Because of chemical, pharmacological, and clinical similarities be tween gemfibrozil and clofibrate, the adverse findings with clofibrate in two large clinica studies may also apply to gemfibrozil. In the first of those studies, the Coronary Drug Project, 1000 subjects with previous myocardial infarction were treated for five years with clofibrate. There was no difference in mortality between the clofibrate-treated subjects and 3000 placebo-treated subjects, but twice as many clofibrate-treated subjects developed cholelithiasis and cholecystitis requiring surgery. In the other study, conducted by the World Health Organization (WHO), 5000 subjects without known coronary heart disease were treated with clofibrate for five years and followed one year beyond. There was a statistically significant, $29 \%$, higher total mortality in the clofibrate treated than in a comparable placebo-treated control group. The excess mortality was due to a $33 \%$ increase in noncardiovascular causes, including malignancy, postcholecystectomy complications, and pancreatitis. The higher risk of clofibrate-treated subjects for gallbladder disease was confirmed.

During the Helsinki Heart Study and in the $1 \frac{1}{2}$ year follow-up period since the tria was completed, mortality from any cause was $59(2.9 \%)$ in the Lopid group and 55 $(2.7 \%)$ in the placebo group. Mortality from any cause during the double-blind portion of the study was 44 deaths in the Lopid group and 43 in the placebo group. Because of the more limited size of the Helsinki Heart Study, this result is not statistically. significantly different from the $29 \%$ excess mortality seen in the clofibrate group in the separate WHO study. Noncoronary heart disease related mortality showed a $58 \%$ greater trend in the Lopid group ( 43 vs 27 patients in the placebo group, $p=0.056$ ) In the Helsinki Heart Study, the incidence of total malignancies discovered during the trial and in the $1 \frac{1}{2}$ years since the trial was completed was 39 in the Lopid group and 29 in the placebo group (difference not statistically significant). This includes 5 basal cell carcinomas in the Lopid group and none in the placebo group $(p=0.06$; historical data predicted an expected 4.7 cases in the placebo group). GI malignancies and deaths from malignancies were not statistically

different between Lopid and placebo subgroups. Follow-up of the Helsinki Heart Study participants will provide further information on cause-specific mortality and cancer morbidity.

2. A gallstone prevalence substudy of 450 Helsinki Heart Study participants showed a
trend toward a greater prevalence of gallstones during the study within the Lopid treatment group $(7.5 \%$ vs $4.9 \%$ for the place bo group, a $55 \%$ excess for the gemfibrozil group). A trend toward a greater incidence of gallbladder surgery was observed for the Lopid group (17 vs 11 subjects, a $54 \%$ ex. cess). This result did not differ statistically

from the increased incidence of cholecystectomy observed in the WHO study in the group treated with clofibrate. Both clofibrate and gemfibrozil may increase cholesterol excretion into the bile leading to cholelithiasis. If cholelithiasis is suspected, gallbladder studies are indicated. Lopid therapy should be discontinued if gallstones are found. 3 . Since a reduction of mortality from coronary artery disease has not been demonstrated and because liver and interstitial cell testicular tumors were increased in rats, Lopid should be administered only to those patients described in the INDICATIONS AND USAGE section. If a significant serum lipid response is not obtained, Lopid should be discontinued.

4. Concomitant Anticoagulants-Caution should be exercised when anticoagulants are given in conjunction with Lopid. The dosage of the anticoagulant should be reduced to maintain the prothrombin time at the desired level to prevent bleeding complications Frequent prothrombin determinations are advisable until it has been definitely determined that the prothrombin level has stabilized.

5. Concomitant therapy with Lopid and Mevacor' (lovastatin) has been associated with rhabdomyolysis, markedly elevated creatine kinase (CK) levels and myoglobinuria, leading in a high proportion of cases to acute renal failure. In most subjects who have had an unsatisfactory lipid response to either drug alone, the possible benefit of combined therapy with lovastatin and gemfibrozil does not outweigh the risks of severe myopathy, rhabdomyolysis, and acute renal failure (See Drug Interactions). The use of fibrates alone, including Lopid, may occasionally be associated with myositis. Patients receiving Lopid and complaining of muscle pain, tenderness, or weakness should have prompt medical evaluation for myositis, including serum creatine kinase level determination. If myositis is suspected or diagnosed, Lopid therapy should be withdrawn.

6. Cataracts - Subcapsular bilateral cataracts occurred in 10\%, and unilateral in $6.3 \%$ of male rats treated with gemfibrozil at 10 times the human dose

PRECAUTIONS. 1. Initial Therapy - Laboratory studies should be done to ascertain that the lipid levels are consistently abnormal. Before instituting Lopid therapy, every attempt should be made to control serum lipids with appropriate diet, exercise, weight loss in obese patients, and control of any medical problems such as diabetes mellitus and hypothyroidism that are contributing to the lipid abnormalities

2. Continued Therapy-Periodic determination of serum lipids should be obtained

and the drug withdrawn if lipid response is inadequate after 3 months of therapy.

3. Drug Interactions - (A) Lovastatin: Rhabdomyolysis has occurred with combined gemfibrozil and lovastatin therapy. It may be seen as early as 3 weeks after initiation of combined therapy or after several months. In most subjects who have had an unsatisfac tory lipid response to either drug alone, the possible benefit of combined therapy with lovastatin and gemfibrozil does not outweigh the risks of severe myopathy, rhabdomyolysis, and acute renal failure. There is no assurance that periodic monitoring of

eatine kinase will prevent the occurrence of severe myopathy and kidney damage

(B) Anticoagulants: CAUTION SHOULD BE EXERCISED WHEN ANTICOAGU LANTS ARE GIVEN IN CONJUNCTION WITH LOPID. THE DOSAGE OF THE ANTI. COAGULANT SHOULD BE REDUCED TO MAINTAIN THE PROTHROMBIN TIME AT THE DESIRED LEVEL TO PREVENT BLEEDING COMPLICATIONS. FREQUENT PROTHROMBIN DETERMINATIONS ARE ADVISABLE UNTIL IT HAS BEEN

DEFINITELY DETERMINED THAT THE PROTHROMBIN IEVEL HAS STABILIZED.

4. Carcinogenesis, Mutagenesis, Impairment of Fertility-Long-term studies have been conducted in rats and mice at one and ten times the human dose. The incidence of benign liver nodules and liver carcinomas was significantly increased in high dose male rats. The incidence of liver carcinomas increased also in low dose males, but this increase was not statistically significant $(p=0.1)$. In high dose female rats, there was a significant increase in the combined incidence of benign, and malignant liver neoplasms. In male and female mice, there were no statistically significant differences
Lopid ${ }^{*}$ (Gemfibrozil Capsules and Tablets)

from controls in the incidence of liver tumors, but the doses tested were lower than those shown to be carcinogenic with other fibrates.

Male rats had a dose-related and statistically significant increase of benign Leydig cell umors at 1 and 10 times the human dose.

Electron microscopy studies have demonstrated a florid hepatic peroxisome proliferation following Lopid administration to the male rat. An adequate study to test for perox isome proliferation has not been done in humans but changes in peroxisome

morphology have been observed. Peroxisome proliferation has been shown to occur in humans with either of two other drugs of the fibrate class when liver biopsies were com. pared before and after treatment in the same individual.

Administration of approximately three or ten times the human dose to male rats for 10 weeks resulted in a dose-related decrease of fertility. Subsequent studies demonstrated that this effect was reversed after a drug-free period of about eight weeks, and it was not transmitted to the offspring.

Pregnancy Category B-Reproduction studies have been performed in the rat at doses 3 and 9 times the human dose, and in the rabbit at 2 and 6.7 times the human dose. These studies have revealed no evidence of impaired fertility in females or harm to the fetus due to Lopid. Minor fetotoxicity was manifested by reduced birth rates observed at the high dose levels. No significant malformations were found among almost 400 offspring from 36 litters of rats and 100 fetuses from 22 litters of rabbits.

There are no studies in pregnant women. In view of the fact that Lopid is tumorigenic in male and female rats, the use of Lopid in pregnancy should be reserved for those patients where the benefit clearly outweighs the possible risk to the patient or fetus

6. Nursing Mothers - Because of the potential for tumorigenicity shown for gem

fibrozil in rats, a decision should be made whether to discontinue nursing or discontinue

the drug, taking into account the importance of the drug to the mother.

Hematologic Changes - Mild hemoglobin, hematocrit and white blood cell decreases have been observed in occasional patients following initiation of Lopid therapy. However, these levels stabilize during long-term administration. Rarely, severe anemia, leukopenia, thrombocytopenia, and bone marrow hypoplasia have been reported. Therefore, periodic blood counts are recommended during the first 12 months opid administration.

8. Liver Function -Abnormal liver function tests have been observed occasionally

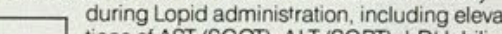
tions of AST (SGOT), ALT (SGPT), LDH, bilirubin, and alkaline phosphatase. These are usually reversible when Lopid is discontinued. Therefore periodic liver function studies are recommended and Lopid therapy should be terminated if abnormalities persist. 9. Use in Children - Safety and efficacy in children have not been established. ADVERSE REACTIONS. In the double-blind controlled phase of the Helsinki Heart Study,
2046 patients received Lopid for up to 5 years. In that study, the following adverse reactions were statistically more frequent in subjects in the Lopid group (placebo incidence in paren theses): gastrointestinal reactions, $34.2 \%$ (23.8\%); dyspepsia, 19.6\% (11.9\%); abdominal pain, $9.8 \%(5.6 \%)$; acute appendicitis (histologically confirmed in most cases where data are available), $1.2 \%(0.6 \%)$; atrial fibrillation, $0.7 \%(0.1 \%)$

Adverse events reported by more than $1 \%$ of subjects, but without a significant difference between groups (placebo incidence in parentheses) were: diarthea, $7.2 \%(6.5 \%)$; fatigue, 3.8\% (3.5\%); nausea/vomiting, $2.5 \%(2.1 \%)$; eczema, $1.9 \%(1.2 \%)$; rash, $1.7 \%$ (1.3\%); vertigo, $1.5 \%(1.3 \%)$; constipation, $1.4 \%(1.3 \%)$; headache, $1.2 \%(1.1 \%)$. Gallbladder surgery was performed in $0.9 \%$ of Lopid and $0.5 \%$ of placebo subjects, a $64 \%$ excess, which is not statistically different from the excess of gallbladder surgery observed in the clofibrate compared to the placebo group of the WHO study.

Nervous system and special senses adverse reactions were more common in the Lopid group. These included hypesthesia, paresthesias, and taste perversion. Other adverse reactions that were more common among Lopid treatment group subjects but where a causal relationship was not established include cataracts, peripheral vascular disease, and intracerebral hemorrhage

From other studies it seems probable that Lopid is causally related to the occurrence of musculoskeletal symptoms (See WARNINGS), and to abnormal liver function tests and hematologic changes (See PRECAUTIONS)

Reports of viral and bacterial infections (common cold, cough, urinary tract infections) were more common in gemfibrozil-treated patients in other controlled clinical trials of 805 patients. Additional adverse reactions that have been reported for gemfibrozil are listed below by system. These are categorized according to whether a causal relationship to treatment with Lopid is probable or not established:

CAUSAL RELATIONSHIP PROBABLE: Gastrointestinal: cholestatic jaundice; Central Nervous System: dizziness, somnolence, paresthesia, peripheral neuritis, decreased libido, depression, headache; Eye: blurred vision; Genitourinary: impotence; Musculoskeletal: myopathy, myasthenia, myalgia, painful extremities, arthralgia, synovitis, rhabdomyolysis (see WARNINGS and Drug Interactions under PRECAU TIONS); Clinical Laboratory: increased creatine phosphokinase, increased bilirubin, in creased liver transaminases (AST [SGOT], ALT [SGPT]), increased alkaline phosphatase; Hematopoietic: anemia, leukopenia, bone marrow hypoplasia, eosinophilia; Im. munologic: angioedema, laryngeal edema, urticaria; Integumentary: exfoliative der. matitis, rash, dermatitis, pruritus.

CAUSAL RELATIONSHIP NOT ESTABLISHED: General: weight loss; Cardiac: extrasys toles; Gastrointestinal: pancreatitis, hepatoma, colitis; Central Nervous System: confusion, convulsions, syncope; Eye: retinal edema; Genitourinary: decreased male fertility Clinical Laboratory: positive antinuclear antibody: Hematopoietic: thrombocytopenia Immunologic: anaphylaxis, Lupus-like syndrome, vasculitis; Integumentary; alopecia DOSAGE AND ADMINISTRATION. The recommended dose for adults is $1200 \mathrm{mg}$ administered in two divided doses 30 minutes before the morning and evening meal MANAGEMENT OF OVERDOSE. While there has been no reported case of overdosage, symptomatic supportive measures should be taken should it occur. References: 1. Frick MH, Elo O, Haapa K, et al: Helsinki Heart Study: Primary prevention trial with gemfibrozil in middle-aged men with dyslipidemia. N Eng/J Med 1987:317:1237-1245. 2. Manninen V, Elo O, Frick MH, et al: Lipid alterations and decline in the incidence of coronary heart disease in the Helsinki Heart Study. JAMA 1988; 260:641-651. 3. Nikkila EA: Familial lipoprotein lipase deficiency and related disorders of chylomicron metabolism. In Stanbury J. B. et al. (eds.): The Metabolic Basis of Inherited Disease, 5th ed., McGraw-Hill, 1983, Chap. 30, pp. 622-642. 